\title{
Adjustments in Motor Unit Properties during Fatiguing Contractions after Training
}

\author{
CAROLINA VILA-CHÃ $\tilde{n}^{1,2}$, DEBORAH FALLA ${ }^{3,4}$, MIGUEL VELHOTE CORREIA ${ }^{2}$, and DARIO FARINA ${ }^{3}$ \\ ${ }^{1}$ Polytechnic Institute of Bragança, Bragança, PORTUGAL; ${ }^{2}$ Faculdade de Engenharia, Universidade do Porto, \\ Porto, PORTUGAL; ${ }^{3}$ Department of Neurorehabilitation Engineering, Bernstein Center for Computational Neuroscience, \\ University Medical Center Göttingen, Georg-August University, Göttingen, GERMANY; and ${ }^{4}$ Pain Clinic, Center for \\ Anesthesiology, Emergency and Intensive Care Medicine, University Hospital Göttingen, Göttingen, GERMANY
}

\begin{abstract}
VILA-CHÃ, C., D. FALLA, M. V. CORREIA, and D. FARINA. Adjustments in Motor Unit Properties during Fatiguing Contractions after Training. Med. Sci. Sports Exerc., Vol. 44, No. 4, pp. 616-624, 2012. Objective: The objective of the study was to investigate the effect of strength and endurance training on muscle fiber membrane properties and discharge rates of low-threshold motor units of the vasti muscles during fatiguing contractions. Methods: Twenty-five sedentary healthy men (age (mean \pm SD) $=26.3 \pm 3.9$ yr) were randomly assigned to one of three groups: strength training, endurance training, or a control group. Conventional endurance and strength training was performed $3 \mathrm{~d} \cdot \mathrm{wk}^{-1}$, during a period of $6 \mathrm{wk}$. Motor unit conduction velocity and EMG amplitude of the vastus medialis obliquus and lateralis muscles and biceps femoris were measured during sustained isometric knee extensions at $10 \%$ and $30 \%$ of the maximum voluntary contraction before and immediately after training. Results: After 6 wk of training, the reduction in motor unit conduction velocity during the sustained contractions at $30 \%$ of the maximum voluntary force occurred at slower rates compared with baseline $(P<0.05)$. However, the rate of decrease was lower after endurance training compared with strength training $(P<0.01)$. For all groups, motor unit discharge rates declined during the sustained contraction $(P<0.001)$, and their trend was not altered by training. In addition, the biceps femoris-vasti coactivation ratio declined after the endurance training. Conclusions: Short-term strength and endurance training induces alterations of the electrophysiological membrane properties of the muscle fiber. In particular, endurance training lowers the rate of decline of motor unit conduction velocity during sustained contractions more than strength training. Key Words: EMG, FATIGUE, SUBMAXIMAL CONTRACTIONS, ENDURANCE TRAINING, STRENGTH TRAINING
\end{abstract}

I mpairment of neuromuscular function develops gradually during submaximal fatiguing contractions $(8,15)$. Although voluntary effort is progressively increased, task failure will eventually occur even if muscles have not been fully activated $(8,9,15)$. The etiology of such impairment is complex and can occur at any site ranging from the cortex to the actin-myosin cross bridges (15). The site of the impairment depends on the task being performed, resulting in different times to failure $(9,15)$. Furthermore, the subject's training background will affect the endurance time limit $(16,36)$.

Several cross-sectional studies have shown that during submaximal sustained contractions, power-trained athletes

\footnotetext{
Address for correspondence: Dario Farina, Ph.D., Department of Neurorehabilitation Engineering, Bernstein Center for Computational Neuroscience, University Medical Center Göttingen, Georg-August University, Von-Siebold-Str. 4, 37075 Göttingen, Germany; E-mail: dario.farina@ bccn.uni-goettingen.de.

Submitted for publication March 2011.

Accepted for publication September 2011.

0195-9131/12/4404-0616/0

MEDICINE \& SCIENCE IN SPORTS \& EXERCISE $_{\circledast}$

Copyright (c) 2012 by the American College of Sports Medicine

DOI: 10.1249/MSS.0b013e318235d81d
}

have lower times to task failure, reaching exhaustion earlier than endurance-trained athletes $(6,36)$. Likewise, after submaximal fatiguing exercise, power-trained athletes show a greater decline in maximal isometric force of the knee extensors than endurance-trained athletes $(16,21,24)$, which is accompanied by a greater decline in peak twitch torque (16) and in conduction velocity (37) but not in changes in the EMG activity pattern of the vasti muscles $(16,37)$. These studies suggests that the distinct neuromuscular fatigue profiles between power- and endurance-trained athletes are mostly due to differences at the peripheral level, in particular, the muscle fiber composition $(6,24,36,37)$. The percentage of slowtwitch fibers in the skeletal muscle is positively correlated with endurance time (21), which explains longer times to task failure for the endurance-trained athletes. However, longitudinal studies show that as few as three sessions of practice of a sustained submaximal isometric contraction of the elbow flexors enable sedentary subjects to prolong their time to exhaustion $(22,38)$. This was accompanied by a lower rate of increase in agonist activity (22) and reduced antagonist inhibition during the prolonged sustained task (38). Therefore, mechanisms other than those occurring at the periphery contribute to an increase in time to failure.

A recent study of our group (40) showed that $6 \mathrm{wk}$ of endurance training results in prolonged time to task failure, 
which is accompanied by a decrease of motor unit discharge rates during brief submaximal contractions. On the contrary, the strength training group showed increased discharge rates during the brief contractions, and both training programs induced similar increments in surface EMG amplitude and muscle fiber conduction velocity in unfatigued muscles. Although neuromuscular adaptations observed in nonfatigued muscles may contribute to differences in time to failure, it is the time course of changes in peripheral and/or central mechanisms that will dictate task failure. Nonetheless, the traininginduced adjustments in the neuromuscular system when fatigue progressively develops during submaximal contractions are not well understood (16). Therefore, the purpose of this study was to investigate the effects of a short-term endurance and a strength training program on the time course of the muscle fiber membrane properties and firing rates of low-threshold motor units of the vastus medialis obliquus and lateralis muscles during prolonged isometric contractions.

\section{METHODS}

\section{Subjects}

Thirty healthy men (age $($ mean $\pm \mathrm{SD})=26.0 \pm 3.8 \mathrm{yr})$ with no history of lower limb disorders participated in the study. None of the subjects were involved in regular strength or endurance training. All subjects gave their informed consent to the procedures of the study. The study was conducted in accordance with the Declaration of Helsinki and approved by the local ethics committee (N-20090032). After the first experimental session (pretraining session), the subjects were randomly assigned to one of three groups: strength training ( $n=10)$, endurance training $(n=10)$, or a control group (no exercise intervention) $(n=10)$. Not all subjects completed the training program. One subject from the strength group and two subjects from the control group did not complete the final experimental session and were excluded from the analysis. In addition, because of technical problems during session 1, the data collected from two subjects (one from each training group) could not be used. Thus, the results are presented for eight subjects in the strength group (age $=25.8 \pm$ $4.2 \mathrm{yr}$, height $=184.0 \pm 6.9 \mathrm{~cm}$, weight $=82.5 \pm 14.3 \mathrm{~kg})$, nine subjects in the endurance group (age $=25.8 \pm 2.8 \mathrm{yr}$, height $=180.9 \pm 6.5 \mathrm{~cm}$, weight $=78.9 \pm 15.0 \mathrm{~kg}$ ), and eight subjects in the control group (age $=27.0 \pm 5.0 \mathrm{yr}$, height $=$ $175.3 \pm 3.4 \mathrm{~cm}$, weight $=78.0 \pm 13.0 \mathrm{~kg})$.

\section{Training Programs}

The training regimens have been described in detail previously (40). Briefly, endurance or strength training was performed during $6 \mathrm{wk}$ for a total of 18 sessions. All training sessions were supervised by an investigator of the study. Endurance training was performed on a bicycle ergometer, and the exercise intensity was prescribed on the basis of the percent of the HR reserve according to the Karvonen method
(23). During the training period, the load intensity ranged between $50 \%$ and $70 \%$ of the HR reserve, and the duration of the sessions ranged between 20 and $50 \mathrm{~min}$. The strength training involved three bilateral leg exercises (leg press, leg extension, and leg curl). The subjects trained with loads of $60 \%-85 \%$ of the one-repetition maximum and performed three to four sets of 8-15 repetitions. For both training programs, the load intensity was applied progressively during the training period.

\section{Procedure}

The subjects attended two laboratory sessions, immediately before (session 1, week 0 ) and after completion of the 6-wk training period (session 2, week 6). For each laboratory session, the subject was comfortably seated on an isokinetic dynamometer (KinCom dynamometer; Chattanooga, TN) with his trunk reclined to $15^{\circ}$ in an adjustable chair and hip and distal thigh firmly strapped to the chair. The rotational axis of the dynamometer was visually aligned with the lateral femoral epicondyle. The right leg was secured to the dynamometer's attachment above the lateral malleolus with the knee at $90^{\circ}$ of flexion. Progressive maximal voluntary contractions (MVCs) of the knee extensors were measured twice, with a 2-min rest in between. The maximum of the two force measures was used as a reference for the definition of the submaximal force levels. In both experimental sessions, the submaximal forces were relative to the MVC measured during the same session. Subjects were then asked to maintain a constant isometric contraction at $10 \% \mathrm{MVC}$ for $70 \mathrm{~s}$. This duration was proven in previous studies to be sufficient for eliciting changes in muscle fiber conduction velocity in the vasti muscles (19). Subjects were provided with online visual feedback of the force exerted, which was displayed on an oscilloscope. The knee extensor force was represented by a bold horizontal line parallel to the target line. Across target forces, the vertical gain on the oscilloscope screen was adjusted to keep the target line approximately in the same position. After $15 \mathrm{~min}$ of rest, the subjects performed an isometric knee extension at 30\% MVC maintaining the force for as long as possible (endurance task). Time to task failure was defined as a drop in force greater than $5 \%$ of the target force level for more than $5 \mathrm{~s}$, after strong verbal encouragement to the subject to maintain the target force. During all submaximal contractions, knee extension force and intramuscular and surface EMG signals were recorded concurrently.

\section{EMG Recordings}

Surface EMG. After skin preparation (shaving, abrasion, and cleaning with water), two adhesive linear arrays of eight electrodes $(5 \times 1 \mathrm{~mm}$ in size, 5-mm interelectrode; Spes Medica, Salerno, Italy) were placed on the vastus lateralis and vastus medialis obliquus, and a pair of surface $\mathrm{Ag}-\mathrm{AgCl}$ electrodes (Ambu Neuroline, Copenhagen, Denmark; conductive area $=28 \mathrm{~mm}^{2}$ ) were placed on the biceps femoris (BF). The arrays of electrodes were located between the 
innervation zone and the distal tendon, along the direction of the muscle fibers (19). The tendon regions, innervation zones, and propagation of the detected motor unit action potentials were identified during preliminary brief knee extensions. For this purpose, a linear array of eight equispaced silver electrodes (LISiN-OT Bioelettronica, Torino, Italy) was used and oriented to observe a clear propagation of the detected motor unit action potentials from the innervation zone to the tendon region, as described previously $(10,28)$. For the BF muscle, the electrodes were placed according to Hermens et al. (20). A ground electrode was placed around the right ankle. Surface EMG signals were amplified as bipolar derivations (EMG amplifier; LISiN-OT Bioelettronica), bandpass filtered ( $-3-\mathrm{dB}$ bandwidth, 10-500 Hz), sampled at 2048 samples per second, and converted to digital data by a 12-bit analog-to-digital converter board.

Intramuscular EMG. Two pairs of wire electrodes (50- $\mu \mathrm{m}$ diameter) made of Teflon-coated stainless steel (A-M Systems, Carlsborg, WA) were inserted with a 23 -gauge needle, 10-20 mm proximal to the surface electrode arrays (10). The wires were uninsulated for $\sim 1 \mathrm{~mm}$ at the tip to detect intramuscular EMG signals. The angle of insertion of the needle was $\sim 45^{\circ}$, and the depth was a few millimeters below the muscle fascia. The needles were removed after insertion, and the wire electrodes were left inside the muscle. Intramuscular EMG signals were amplified as bipolar derivations (Counterpoint EMG; Dantec Medical, Skovlunde, Denmark), bandpass filtered $(500 \mathrm{~Hz}-4 \mathrm{kHz})$, sampled at $10,000 \mathrm{~Hz}$, and stored after 12-bit analog-to-digital conversion.

\section{Subcutaneous Fat Layer Thickness}

Estimation of motor unit conduction velocity is affected by the thickness of the subcutaneous fat layer (11). With training, this factor can be altered resulting in changes of the motor unit conduction velocity. Thus, the subcutaneous tissue thickness of the subjects participating in the training programs was assessed before and after training by ultrasound B-mode imaging (Acuson XP 180; Mountain View, CA). The probe (10 MHz, linear $38 \mathrm{~mm}$ ) was placed both proximal and distal to the location of the array electrodes, and the thickness was measured between the dermis of the skin and fascia.

\section{Signal Analysis}

Motor unit conduction velocity and average rectified value were calculated in two intervals of 10 -s duration. For both isometric contractions (at 10\% and 30\% MVC), the first interval $\left(\mathrm{T}_{1}\right)$ was defined at the beginning (from 0 to $10 \mathrm{~s}$ ) of the contraction, and the second interval $\left(\mathrm{T}_{2}\right)$ corresponds to the time after $1 \mathrm{~min}$ of the sustained contraction (from 60 to $70 \mathrm{~s}$ ).

For the contraction at $30 \%$ MVC sustained until task failure, two additional intervals of $10 \mathrm{~s}$ were used to analyze the average rectified value. These intervals were set $10 \mathrm{~s}$ before $50 \%$ and before $100 \%$ of the time to task failure (designated as $\mathrm{T}_{3}$ and $\mathrm{T}_{4}$, respectively). Motor unit conduction velocity was not estimated for these additional intervals be- cause the intramuscular signal became progressively more interferential, making it difficult to accurately track the same motor units over time.

The time course of the average rectified value of the vastus lateralis and vastus medialis obliquus, over different time intervals $\left(T_{2}, T_{3}\right.$, and $\left.T_{4}\right)$, was calculated by subtracting the values of the respective interval $\left(T_{2}, T_{3}\right.$, and $\left.T_{4}\right)$ from the initial values $\left(\mathrm{T}_{1}\right)$. The time course of motor unit conduction velocity and motor unit discharge rates were estimated only for the time interval $\mathrm{T}_{2}$.

Decomposition of intramuscular signals and motor unit conduction velocity estimation. The recorded intramuscular signals were decomposed into the constituent motor unit action potentials by a decomposition algorithm previously validated (29). Unusually short $(<20 \mathrm{~ms})$ or long $(>200 \mathrm{~ms})$ time intervals between subsequent detected discharges of the individual motor units were manually reanalyzed and corrected when necessary. For both sustained contractions, only the motor units that were active during $T_{1}$ and $\mathrm{T}_{2}$ were used to compute the motor unit conduction velocity. The mean discharge rate (pulses per second (pps)) and interspike interval variability were computed from the motor unit spike trains. Conduction velocity of the individual motor units was estimated from the averaged multichannel surface potentials by a spike-triggered average technique previously described (10). Briefly, the detected times of occurrence of individual motor unit action potentials in the intramuscular signals were used as trigger for averaging the multichannel surface EMG signals from which a multichannel maximum likelihood method was used to estimate motor unit conduction velocity (13). A minimum of 70 triggers were used for each motor unit in each of the time intervals analyzed. A window of $50 \mathrm{~ms}$ centered on the time instant of detected motor unit action potentials was used for the average of the surface signals. To reduce the effects of the nonpropagating components, double differential signals (obtained by subtracting two adjacent single differential signals) were used for the estimation. The channels used for the conduction velocity estimation were manually selected. Only the channels showing similar propagating motor unit action potentials were accepted for analysis. For each experimental session, the same channels were selected for all motor units recorded from the same subject.

Surface EMG amplitude. The average rectified value was estimated from the same channels used for motor unit conduction velocity estimation. For each time interval, the average rectified value was estimated in consecutive nonoverlapping epochs of $1 \mathrm{~s}$ and then averaged. The level of coactivation was quantified by computing the ratio between the antagonist and agonist (average across both vasti muscles) EMG signals.

\section{Statistical Analysis}

The effects of the training programs on the average rectified value of the vastus lateralis, vastus medialis obliquus, 
and $\mathrm{BF}$ and the motor unit conduction velocity and motor unit discharge rates of the vastus lateralis and vastus medialis obliquus were evaluated with four-way repeated-measures ANOVA with group (control, endurance, and strength), training period (weeks 0 and 6$)$, time intervals $\left(\left(\mathrm{T}_{1}, \mathrm{~T}_{2}, \mathrm{~T}_{3}\right.\right.$, and $\mathrm{T}_{4}$ ) or $\left(\mathrm{T}_{1}\right.$ and $\left.\mathrm{T}_{2}\right)$ ), and muscle (vastus lateralis and vastus medialis obliquus) as factors. The effects of training on the time course of motor unit conduction velocity and discharge rates of the vastus lateralis and vastus medialis obliquus over time were assessed with three-way repeated-measure ANOVA with group, training period, and muscle as factors. In addition, changes in the time course of the vasti average rectified value were assessed with a four-way repeated-measures ANOVA with group, training period, time intervals, and muscle as factors. A two-way repeated-measure ANOVA with group and training period as factors was applied to assess changes in the MVC, time to task failure, and subcutaneous tissue thickness. Before conducting each repeated-measure ANOVA, the normality and equality of covariance matrices were tested. Because of the sample size and because few cells of some dependent variables violated the normality assumption, the Pillai trace omnibus statistic was used in preference to the Wilks $\lambda$ (39). In addition, the Mauchly sphericity test was computed, and when the sphericity assumption was violated, a Greenhouse-Geisser adjustment was made. When ANOVA was significant, the post hoc Student-Newman-Keuls test for pairwise comparisons was applied. Statistical significance was designated at $P<0.05$ for all comparisons. Results are reported as means and SD in the text and as mean and SE in the figures.

\section{RESULTS}

No differences were observed between groups for age, height, and weight. Moreover, no differences were observed between the groups for any of the motor output or electrophysiological parameters assessed in the first experimental session (before training).

Before training, the thickness of the subcutaneous tissue was $5.1 \pm 1.7$ and $5.2 \pm 1.6 \mathrm{~mm}$ for the endurance and strength groups, respectively (average of the distal and proximal measures obtained for the lateral and medial sides of the leg). After $6 \mathrm{wk}$ of training, the subcutaneous tissue thickness remained unchanged (endurance group $=5.2 \pm$ $1.6 \mathrm{~mm}$, strength group $=5.3 \pm 1.7 \mathrm{~mm}, P>0.56$, for each group).

Motor output. After $6 \mathrm{wk}$ of endurance training, time to task failure increased by $29.2 \% \pm 13.7 \%$ (from $119.7 \pm 33.8$ to $154.3 \pm 42.2 \mathrm{~s}, P<0.05$ ), but no significant changes were observed in MVC (from 525.1 \pm 98.9 to $500.4 \pm 92.3 \mathrm{~N}$ ). In contrast, strength training induced an increase in the MVC force by $16.8 \% \pm 8 \%$ (from $520.1 \pm 112.1$ to $603.7 \pm 111.2 \mathrm{~N}$, $P<0.05$ ) but did not influence time to task failure (from $159.8 \pm 46.9$ to $170.9 \pm 74.4 \mathrm{~s})$. None of the motor output parameters changed in the control group $(\mathrm{MVC}=$ from
$549.5 \pm 68.5$ to $554.4 \pm 47.2 \mathrm{~N}$, time to task failure $=$ from $128.8 \pm 69.1$ to $123.7 \pm 73.3 \mathrm{~s}$ ).

Motor unit behavior. The alterations induced by the training programs showed similar trends for the vastus lateralis and vastus medialis obliquus muscles. Because no interactions between muscle and time were observed $(P>0.51$, for all variables), the results presented in the figures correspond to the average of both vasti muscles.

From all sessions, a total of 820 motor units were identified in $T_{1}$, and only 536 motor units could be tracked in $T_{2}$. The motor unit conduction velocity was computed only for the motor units that could be identified in both time intervals. The number of motor units identified for each subject in each experimental session ranged between 1 and 7 at each force level and for each muscle (average $=2.7$ motor units in each condition).

The discharge rate of the detected motor units decreased over time, in particular, at 30\% MVC $(P<0.001)$. After $60 \mathrm{~s}$ of sustained contraction at $30 \% \mathrm{MVC}$, the discharge rate of vasti motor units decreased between $0.6 \pm 0.2$ and $1.1 \pm$ 0.3 pps (Fig. 1). The decline of the discharge rate over time was not influenced by any of the training programs (interaction between group and time, $P>0.60$; Fig. 1).

Motor unit conduction velocity. Figure 2 shows the motor unit conduction velocity for the vasti muscles during the submaximal isometric contractions.

The motor unit conduction velocity values at the beginning of the contractions were dependent on the force level and training period. At $30 \% \mathrm{MVC}$, the initial motor unit conduction velocity was $74.0 \% \pm 10.2 \%$ higher than at $10 \%$ MVC $(P<0.001)$. The effect of the training programs was only observed at the higher force level (Fig. 2). After $6 \mathrm{wk}$ of endurance and strength training, the initial motor unit conduction velocity of the vasti muscles increased by $10.3 \% \pm$ $8.8 \%$ and $11.1 \% \pm 10.0 \%$, respectively, whereas no changes were observed for the control group (Fig. 2).

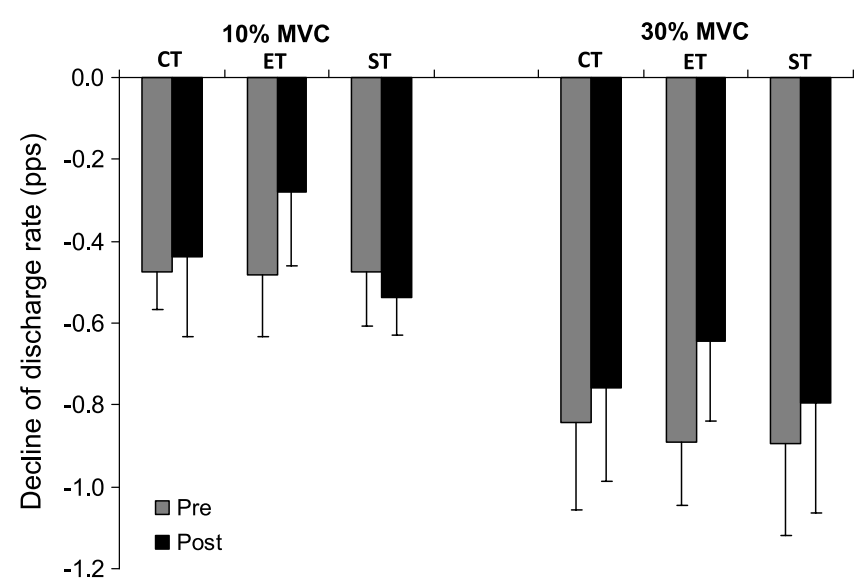

FIGURE 1-Mean \pm SE for the decline of the discharge rates of motor units of the vasti muscles (average of vastus medialis obliquus and vastus lateralis) recruited at the onset of the sustained knee extension contractions at $10 \%$ and $30 \%$ MVC for all groups, before and after training. 

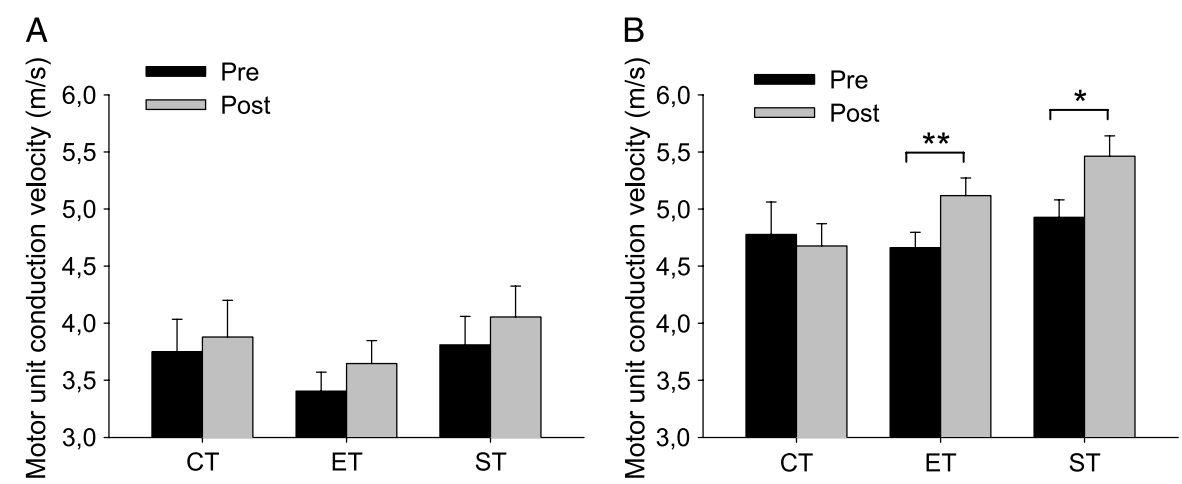

FIGURE 2-Mean \pm SE for the initial values of motor unit conduction velocity of the vasti muscles at $10 \%$ MVC (A) and $30 \%$ MVC (B), for all groups, before and after training. $* P<0.05$ from week 0 to week $6 . * * P<0.001$ from week 0 to week 6 .

Motor unit conduction velocity decreased during the sustained contractions. The decline in motor unit conduction velocity over time was load and training dependent $(P<0.05$; Fig. 3). At $30 \% \mathrm{MVC}$, the decline was greater $(-5.3 \% \pm$ $2.3 \%)$ than at $10 \% \operatorname{MVC}(-3.4 \% \pm 1.9 \%)$.

At $30 \% \mathrm{MVC}$, the reduction in motor unit conduction velocity over time was lower after both training programs (Fig. 3). Nonetheless, for the sustained contraction at $30 \%$ MVC, the endurance group showed a lower decline in motor unit conduction velocity than the strength group $(P<0.01$; Fig. 3). No alterations were observed in the control group.

Surface EMG amplitude. Figure 4 shows the EMG amplitude of the vasti muscles during the submaximal contractions for all groups, over each experimental session. After both training programs, the average rectified value of the vasti muscles increased in all time intervals analyzed for the contraction at $30 \%$ MVC (interaction between time, interval, and group: $P<0.05$; Fig. $4 \mathrm{~B}, \mathrm{C}$ ), whereas no changes were observed in the control group (Fig. 4A).

The average rectified value of the vasti muscles increased progressively throughout the endurance task (main effect

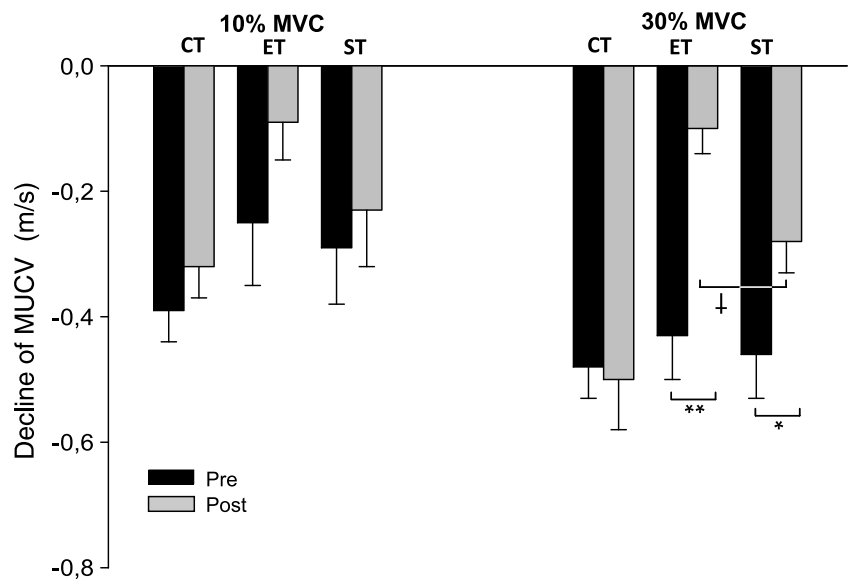

FIGURE 3-Mean \pm SE for the decline in motor unit conduction velocity in the vasti muscles (average of vastus medialis obliquus and vastus lateralis) during sustained knee extension contractions at $\mathbf{1 0 \%}$ and $30 \%$ of $\mathrm{MVC}$ for all groups, before and after training. $* P<0.05$ from week 0 to week 6 . $* * P<0.001$ from week 0 to week 6 . $\dagger$ Decline in motor unit conduction velocity after training was lower for the endurance than for the strength group $(P<0.01)$. interval, $P<0.0001)$. For all groups, at the end of the endurance task, the average rectified value of the vasti was $49.2 \% \pm 22.9 \%$ to $66.1 \% \pm 17.2 \%$ higher than at the beginning of the contraction (Fig. 5). No interaction between group and time was observed for the rate of increase of the vasti average rectified value $\left(P=0.09, \eta_{p}{ }^{2}=0.14\right.$ and observed power $=0.58)($ Fig. 5).

The EMG amplitude of BF also increased progressively throughout the sustained contractions (interval effect $P<0.001$, for both isometric contractions) and was influenced by both training programs (interaction group $\times$ time $\times$ interval, $P<0.001$; Fig. 6). After endurance training, the average rectified value of the BF was lower than before training, in particular, during the time intervals $\mathrm{T}_{2}$ and $\mathrm{T}_{3}(P<0.01$ for both time intervals; Fig. 6B). In contrast, after strength training, the average rectified value of the $\mathrm{BF}$ increased, particularly during the last two time intervals $(P<0.01$ and $P<0.001$ for $\mathrm{T}_{3}$ and $\mathrm{T}_{4}$, respectively; Fig. $6 \mathrm{C}$ ).

The alterations in both the agonist and antagonist muscle activity observed after endurance training influenced the coactivation ratio. After $6 \mathrm{wk}$ of endurance training, the level of coactivation was reduced by $36.8 \% \pm 22.3 \%(P<0.05)$. No changes in the coactivation were found for the strength or control group ( $P>0.80$, for both groups).

\section{DISCUSSION}

The purpose of the study was to investigate the effects of distinct training programs on the time course of the muscle fiber membrane properties of low-threshold motor units and EMG activity of the vasti muscles during submaximal fatiguing contractions. The main finding is that, after $6 \mathrm{wk}$ of either endurance or strength training, the rate of decline over time of the motor unit conduction velocity was reduced, mostly for the endurance group. In addition, the BF-vasti coactivation ratio decreased, after endurance training.

\section{Motor Performance}

Six weeks of endurance and strength training induced specific changes in motor performance. Endurance training improved time to task failure with no changes in MVC, 
A

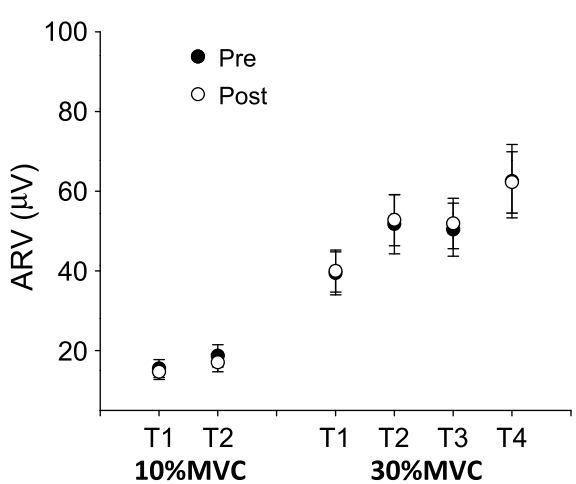

B

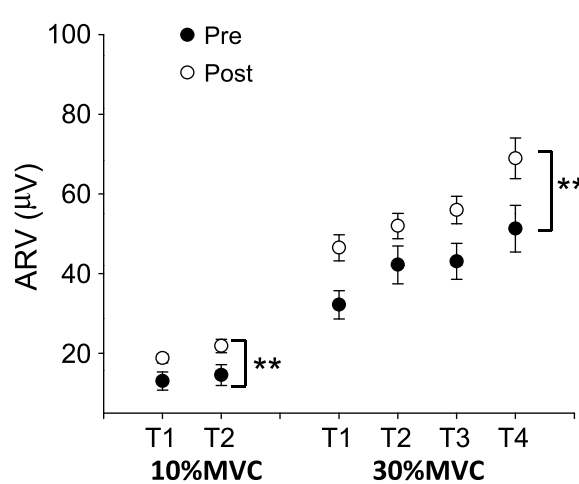

C

STRENGTH

FIGURE 4-Mean $\pm \mathrm{SE}$ for the average rectified value of the vasti muscles obtained during submaximal isometric knee extension contractions at $10 \%$ and $30 \% \mathrm{MVC}$, across experimental sessions for the control group (A), endurance group (B), and strength group (C). The data represent the average of the average rectified value of the vasti muscles obtained for the time intervals $T_{1}, T_{2}, T_{3}$, and $T_{4} \cdot * P<0.05$ from week 0 to week 6 . **P<0.001 from week 0 to week 6.

whereas strength training enhanced MVC and did not affect time to task failure.

\section{Electrophysiological Variables during Sustained Submaximal Contractions}

Time course of motor unit conduction velocity. Changes of the peripheral neuromuscular system induced by fatiguing contractions can be detected by investigating changes in motor unit conduction velocity (12). During the sustained submaximal contractions, the motor unit conduction velocity decreased likely because of alterations of the sarcolemmal excitability (25). The generation of action potentials induces cellular $\mathrm{K}^{+}$efflux and $\mathrm{Na}^{+}$and $\mathrm{Cl}^{-}$influx, causing perturbations in the intracellular and extracellular $\mathrm{K}^{+}$ and $\mathrm{Na}^{+}$gradient concentrations (31). These alterations depolarize the sarcolemmal and t-tubular membranes, which reduce membrane excitability $(7,25)$. The loss of membrane excitability is partly counteracted by the $\mathrm{Na}^{+}-\mathrm{K}^{+}$pump activity, which, however, is not sufficient to fully balance the
$\mathrm{K}^{+}$efflux $(7,33)$. Thus, during sustained contractions, the velocity of propagation of the action potential decreases, even at very low force levels (33). In addition, with continued muscle contraction, an increase in the concentration of $\mathrm{H}^{+}$ ions can occur, contributing to the change in membrane excitability (15).

This study showed that the rate of decline of motor unit conduction velocity during sustained contractions was slower after 6 wk of either endurance or strength training with respect to baseline. Although both groups showed similar adaptations, the decline in motor unit conduction velocity was reduced to a greater extent after endurance training. The observed alterations may reflect changes in the $\mathrm{Na}^{+}-\mathrm{K}^{+}$pump concentration (content and/or activity). The $\mathrm{Na}^{+}-\mathrm{K}^{+}$pump is a determinant for the regulation of the $\mathrm{Na}^{+}-\mathrm{K}^{+}$distribution and maintenance of membrane excitability during muscle contractions $(30,33)$. Thus, an upregulation of pump concentration would prolong the balance of $\mathrm{Na}^{+}-\mathrm{K}^{+}$concentration gradients, protecting the muscle contractibility against fatigue $(7,31)$.
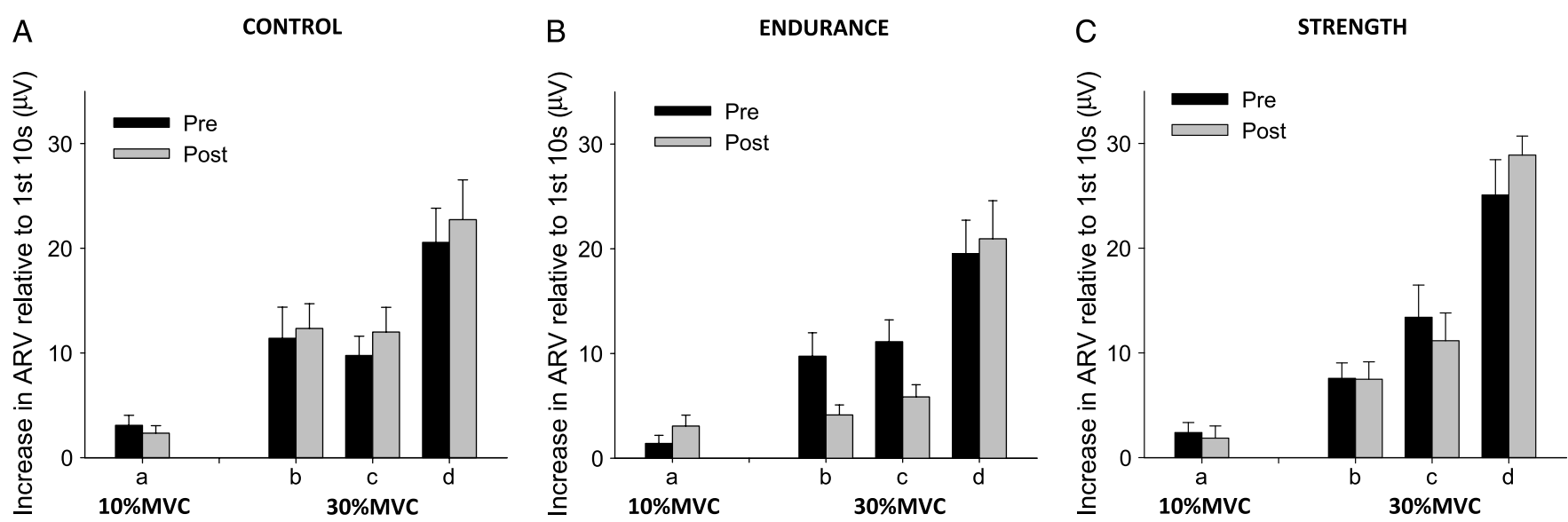

FIGURE 5-Mean \pm SE for the changes in average rectified value of the vasti muscles at two submaximal isometric knee extension contractions $(10 \%$ and $30 \%$ MVC) over experimental sessions for the control group (A), endurance group (B), and strength group (C). The changes over different time intervals $\left(T_{2}, T_{3}\right.$, and $\left.T_{4}\right)$ were computed relative to the initial time interval $\left(T_{1}\right) . * P<0.05$ from week 0 to week 6 . 

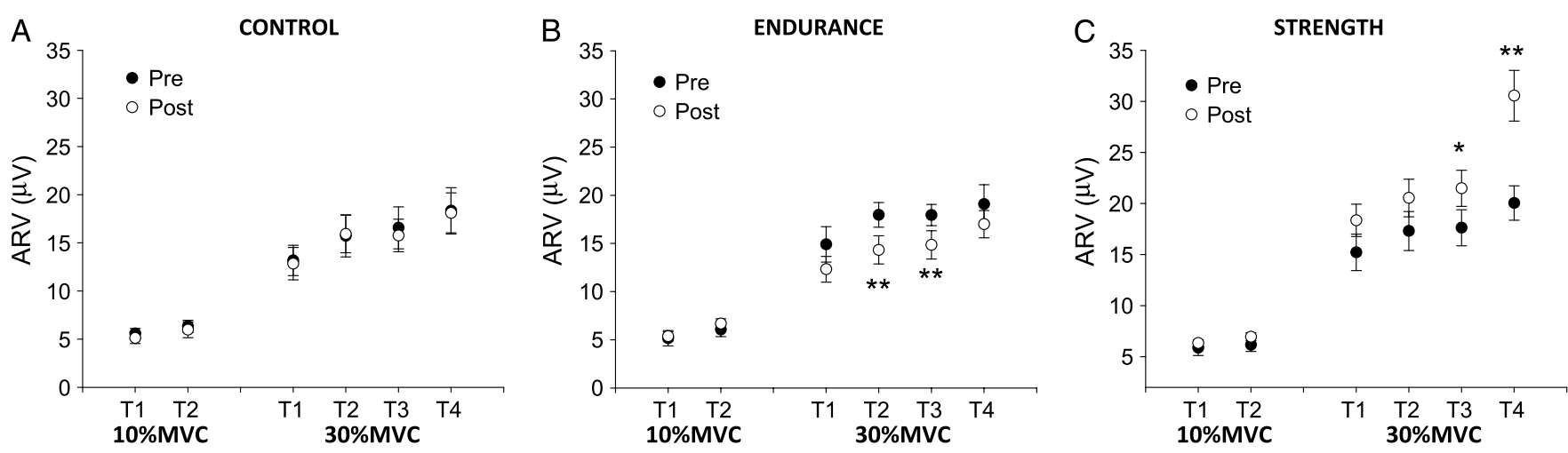

FIGURE 6-Mean $\pm \mathrm{SE}$ for the average rectified value of the $\mathrm{BF}$ obtained during submaximal isometric knee extension contractions at $10 \%$ and $30 \%$ MVC, across experimental sessions for the control group (A), endurance group (B), and strength group (C). The data represent the average of the average rectified value of the vasti obtained for the time intervals $T_{1}, T_{2}, T_{3}$, and $T_{4} * P<0.05$ from week 0 to week 6 . **P<0.001 from week 0 to week 6 .

It has been shown that regular physical activity of moderate to high intensities increases the $\mathrm{Na}^{+}-\mathrm{K}^{+}$pump concentration, independently of the type of training (7). Increased $\mathrm{Na}^{+}-\mathrm{K}^{+}$pump concentration has been observed after endurance training (17), strength training (17), and sprint training (32). Nevertheless, the time course of this adaptation may differ between different types of training. Green et al. (17) demonstrated that after 3 wk of high-volume cycling $(2 \mathrm{~h}$, six times per week), the $\mathrm{Na}^{+}-\mathrm{K}^{+}$pump concentration increased significantly in the vastus lateralis muscle, whereas 7 wk of strength training (three leg exercises, three times per week) was required to induce similar adaptations. The adaptation of the $\mathrm{Na}^{+}-\mathrm{K}^{+}$pump concentration is associated with contractile activity and with a concomitant upregulation of oxidative metabolism $(17,18)$, which may explain the faster adaptations after endurance training compared with strength training. Different time courses of the $\mathrm{Na}^{+}-\mathrm{K}^{+}$pump adaptation may explain the differences in the rate of decline of motor unit conduction velocity between the endurance and strength groups in the present study. Furthermore, such adaptation of the $\mathrm{Na}^{+}-\mathrm{K}^{+}$pump enables fast conduction of the action potentials (7), which may have contributed toward the higher initial motor unit conduction velocity values after both training programs.

Alterations of the conduction velocity may also be due to other training effects, such as an increase in the diameter of the muscle fibers (2) or reduction in the thickness of the fat layer beneath the surface electrodes (11). However, an increase in muscle fiber diameter is typically induced by strength training, not endurance training, which may even reduce fiber diameter (26). Alterations in subcutaneous tissue thickness can also be ruled out because the thickness of tissue beneath the electrode arrays was not affected by either training program.

Conduction velocity is also influenced by changes in motor unit discharge rates $(12,34)$. However, in the present study, the initial motor unit conduction velocity values showed a similar increment after both training programs, despite opposite adjustments in the initial mean discharge rates. Thus, it is unlikely that the changes observed in motor unit conduction velocity after training are due to changes in motor unit discharge rates.

Time course of the EMG amplitude. During the endurance task at $30 \%$ MVC, the activity of the vasti muscles increased progressively reaching approximately twofold the initial values by the end of the task, independently of the group or training period. The progressive increment of the EMG amplitude reflects an increase of the excitation of the motoneuron pool $(3,14)$. As fatigue develops, recruitment of additional motor units occurs to compensate for the reduction of the force-generating capacity of the initially recruited motor units (15). Concomitantly, the motor unit discharge rates may remain constant, increase, or decrease $(1,5)$; however, typically, motor units recruited at the beginning of the task will reduce their discharge rate over a sustained contraction $(1,3)$. In the present study, the surface EMG amplitude of the vasti muscles increased, whereas the discharge rates of the initially recruited motor units decreased significantly after $60 \mathrm{~s}$ of the sustained contraction. These data suggest that the submaximal force level was maintained because of recruitment of additional motor units, which is in accordance with previous studies $(3,5)$. Both the rate of decline in discharge rate of the initial active motor units and the rate of increase of the EMG amplitude were not significantly affected by either training program. Nevertheless, it has been shown that a short interval of practice of a fatiguing sustained contraction improves the endurance time and reduces the rate of increase of the EMG activity of the agonist muscles $(22,38)$. Despite the nonlinear summation of the motor unit action potentials in the EMG signal (13), this might indicate that after endurance training, the recruitment of the motoneuron pool occurred at slower rates than before training, contributing to a longer endurance time (22).

Endurance training induces various physiological adaptations, such as increased $\mathrm{Na}^{+}-\mathrm{K}^{+}$pump activity and increased energy metabolic potential $(7,17)$, which leads to a slower rate of increase of metabolic by-products during sustained contractions. Afferent feedback on muscle milieu 
is provided by intramuscular receptors, particularly by group III-IV muscle afferents. These afferents are sensitive to metabolic by-products of the muscle contraction, such as an increase in the extracellular potassium (4). The discharge of these afferents in response to such stimuli acts in a complex manner over several points of the pathways responsible for force production (15). Their activity contributes to a compression of the recruitment thresholds of the high threshold motoneurons (27), which would lead to recruitment of additional motor units but with lower firing rates in generating the target force level (4). Therefore, a slower rate of increase of metabolic by-products of the contraction would presumably account for a slower rate of increase of the discharge rates of the group III-IV afferents and, consequently, a slower recruitment of the motoneuron pool over the sustained contraction. Such alterations would contribute to increased endurance time after training.

Other mechanisms may also account for improvements in the endurance capacity during sustained contractions $(9,22)$. In the present study, the coactivation of the BF was lower after endurance training, whereas it did not change after strength training. Some cross-sectional studies report a lower coactivation ratio in endurance-trained athletes compared with power athletes (35); however, others report no difference (16) during unfatigued contractions. During dynamic fatiguing exercise, the coactivation of the hamstring muscles increases in power-trained athletes but not in endurance-trained ath-

\section{REFERENCES}

1. Adam A, De Luca CJ. Firing rates of motor units in human vastus lateralis muscle during fatiguing isometric contractions. $J$ Appl Physiol. 2005;99(1):268-80.

2. Andreassen S, Arendt-Nielsen L. Muscle fibre conduction velocity in motor units of the human anterior tibial muscle: a new size principle parameter. J Physiol. 1987;391:561-71.

3. Bigland-Ritchie B, Cafarelli E, Vollestad NK. Fatigue of submaximal static contractions. Acta Physiol Scand Suppl. 1986;556: 137-48.

4. Bigland-Ritchie BR, Dawson NJ, Johansson RS, Lippold OC Reflex origin for the slowing of motoneurone firing rates in fatigue of human voluntary contractions. J Physiol. 1986;379:451-9.

5. Carpentier A, Duchateau J, Hainaut K. Motor unit behaviour and contractile changes during fatigue in the human first dorsal interosseus. J Physiol. 2001;534(Pt 3):903-12.

6. Clarkson PM, Kroll W, McBride TC. Plantar flexion fatigue and muscle fiber type in power and endurance athletes. Med Sci Sports Exerc. 1980;12(4):262-7.

7. Clausen $\mathrm{T} . \mathrm{Na}^{+}-\mathrm{K}^{+}$pump regulation and skeletal muscle contractility. Physiol Rev. 2003;83(4):1269-324.

8. Enoka RM, Baudry S, Rudroff T, Farina D, Klass M, Duchateau J. Unraveling the neurophysiology of muscle fatigue. J Electromyogr Kinesiol. 2011;21(2):208-19.

9. Enoka RM, Duchateau J. Muscle fatigue: what, why and how it influences muscle function. J Physiol. 2008;586(1):11-23.

10. Farina D, Arendt-Nielsen L, Merletti R, Graven-Nielsen T. Assessment of single motor unit conduction velocity during sustained contractions of the tibialis anterior muscle with advanced spike triggered averaging. J Neurosci Methods. 2002;115(1):1-12.

11. Farina D, Cescon C, Merletti R. Influence of anatomical, physical, and detection-system parameters on surface EMG. Biol Cybern 2002;86:445-56. letes, whereas during isometric contractions, no change was reported for either group (16). Whereas the results from cross-sectional studies are inconsistent, a longitudinal study showed that reduced antagonist inhibition was associated to increased time to task failure (38). Thus, reduced coactivation may have also contributed to the increased endurance time observed for the endurance group in this study.

\section{CONCLUSIONS}

The rate of decline of motor unit conduction velocity during sustained contractions was reduced after $6 \mathrm{wk}$ of both endurance and strength training; however, a greater reduction is observed after endurance training. In addition, endurance training reduces the level of coactivation between the vasti and $\mathrm{BF}$ during sustained contractions of knee extension. These alterations likely contribute to longer times to task failure after endurance training.

Carolina Vila-Chã was supported by Fundação para a Ciência e Tecnologia of Portugal (Ph.D. grant ID, SFRH/BD/31796/2006). Part of the study was supported by the European Research Council Advanced Research Grant DEMOVE ("Decoding the Neural Code of Human Movements for a New Generation of Man-Machine Interfaces," no. 267888) (D.F.).

The authors declare no conflict of interest.

The results of the present study do not constitute endorsement by the American College of Sports Medicine.

12. Farina D, Gazzoni M, Camelia F. Low-threshold motor unit membrane properties vary with contraction intensity during sustained activation with surface EMG visual feedback. J Appl Physiol. 2004;96(4):1505-15; discussion.

13. Farina D, Merletti R, Enoka RM. The extraction of neural strategies from the surface EMG. J Appl Physiol. 2004;96(4):1486-95.

14. Fuglevand AJ, Zackowski KM, Huey KA, Enoka RM. Impairment of neuromuscular propagation during human fatiguing contractions at submaximal forces. J Physiol. 1993;460:549-72.

15. Gandevia SC. Spinal and supraspinal factors in human muscle fatigue. Physiol Rev. 2001;81(4):1725-89.

16. Garrandes F, Colson SS, Pensini M, Seynnes O, Legros P. Neuromuscular fatigue profile in endurance-trained and power-trained athletes. Med Sci Sports Exerc. 2007;39(1):149-58.

17. Green H, Dahly A, Shoemaker K, Goreham C, Bombardier E, Ball-Burnett M. Serial effects of high-resistance and prolonged endurance training on $\mathrm{Na}^{+}-\mathrm{K}^{+}$pump concentration and enzymatic activities in human vastus lateralis. Acta Physiol Scand. 1999;165(2):177-84.

18. Green HJ, Barr DJ, Fowles JR, Sandiford SD, Ouyang J. Malleability of human skeletal muscle $\mathrm{Na}(+)-\mathrm{K}(+)$-ATPase pump with short-term training. J Appl Physiol. 2004;97(1):143-8.

19. Hedayatpour N, Arendt-Nielsen L, Farina D. Motor unit conduction velocity during sustained contraction of the vastus medialis muscle. Exp Brain Res. 2007;180(3):509-16.

20. Hermens H, Freriks B, Merletti R, et al. European Recommendations for Surface Electromyography. Results of the SENIAM Project. Roessingh Research and Development; 1999. p. 15-54.

21. Hulten B, Thorstensson A, Sjodin B, Karlsson J. Relationship between isometric endurance and fibre types in human leg muscles. Acta Physiol Scand. 1975;93(1):135-8. 
22. Hunter SK, Enoka RM. Changes in muscle activation can prolong the endurance time of a submaximal isometric contraction in humans. J Appl Physiol. 2003;94(1):108-18.

23. Karvonen MJ, Kentala E, Mustala O. The effects of training on heart rate; a longitudinal study. Ann Med Exp Biol Fenn. 1957;35(3): 307-15.

24. Komi PV, Tesch P. EMG frequency spectrum, muscle structure, and fatigue during dynamic contractions in man. Eur J Appl Physiol Occup Physiol. 1979;42(1):41-50.

25. Kossler F, Lange F, Caffier G, Kuchler G. External potassium and action potential propagation in rat fast and slow twitch muscles. Gen Physiol Biophys. 1991;10(5):485-98.

26. Malisoux L, Francaux M, Theisen D. What do single-fiber studies tell us about exercise training? Med Sci Sports Exerc. 2007;39(7): 1051-60.

27. Martin PG, Weerakkody N, Gandevia SC, Taylor JL. Group III and IV muscle afferents differentially affect the motor cortex and motoneurones in humans. J Physiol. 2008;586(5):1277-89.

28. Masuda T, Miyano H, Sadoyama T. The distribution of myoneural junctions in the biceps brachii investigated by surface electromyography. Electroencephalogr Clin Neurophysiol. 1983;56(6): 597-603.

29. McGill KC, Lateva ZC, Marateb HR. EMGLAB: an interactive EMG decomposition program. J Neurosci Methods. 2005;149(2): 121-33.

30. McKenna MJ. Effects of training on potassium homeostasis during exercise. J Mol Cell Cardiol. 1995;27(4):941-9.

31. McKenna MJ, Bangsbo J, Renaud JM. Muscle $\mathrm{K}^{+}, \mathrm{Na}^{+}$, and $\mathrm{Cl}$ disturbances and $\mathrm{Na}^{+}-\mathrm{K}^{+}$pump inactivation: implications for fatigue. J Appl Physiol. 2008;104(1):288-95.
32. McKenna MJ, Schmidt TA, Hargreaves M, Cameron L, Skinner SL, Kjeldsen K. Sprint training increases human skeletal muscle $\mathrm{Na}(+)-\mathrm{K}(+)-$ ATPase concentration and improves $\mathrm{K}^{+}$regulation. J Appl Physiol. 1993;75(1):173-80.

33. Nielsen $\mathrm{OB}$, Clausen $\mathrm{T}$. The $\mathrm{Na}^{+} / \mathrm{K}(+)$-pump protects muscle excitability and contractility during exercise. Exerc Sport Sci Rev. 2000;28(4):159-64.

34. Nishizono H, Kurata H, Miyashita M. Muscle fiber conduction velocity related to stimulation rate. Electroencephalogr Clin Neurophysiol. 1989;72(6):529-34.

35. Osternig LR, Hamill J, Lander JE, Robertson R. Co-activation of sprinter and distance runner muscles in isokinetic exercise. Med Sci Sports Exerc. 1986;18(4):431-5.

36. Paasuke M, Ereline J, Gapeyeva H. Neuromuscular fatigue during repeated exhaustive submaximal static contractions of knee extensor muscles in endurance-trained, power-trained and untrained men. Acta Physiol Scand. 1999;166(4):319-26.

37. Rainoldi A, Gazzoni M, Merletti R, Minetto MA. Mechanical and EMG responses of the vastus lateralis and changes in biochemical variables to isokinetic exercise in endurance and power athletes. J Sports Sci. 2008;26(3):321-31.

38. Riley ZA, Baudry S, Enoka RM. Reflex inhibition in human biceps brachii decreases with practice of a fatiguing contraction. J Neurophysiol. 2008;100(5):2843-51.

39. Tabachnick BG, Fidell LS. Using Multivariate Statistics. Needham Heights (MA): Allyn \& Bacon; 2006. p. 78-91.

40. Vila-Cha C, Falla D, Farina D. Motor unit behavior during submaximal contractions following six weeks of either endurance or strength training. J Appl Physiol. 2010;109(5):1455-66. 